\title{
Study on Friction and Wear Properties of Pantograph Strip/Copper Contact Wire for High-Speed Train
}

\author{
Tao Ding ${ }^{*}$, , Wenjing Xuan ${ }^{2}$, Qiudong $\mathrm{He}^{1}$, Hao $\mathrm{Wu}^{1}$ and Wei Xiong ${ }^{1}$ \\ ${ }^{I}$ Department of Mechanical Engineering, Hubei Engineering University, Xiaogan 432000, China \\ ${ }^{2}$ College of Technology, Hubei Engineering University, Xiaogan 432000, China
}

\begin{abstract}
A series of experiments on friction and wear properties of carbon strip rubbing against copper contact wire is performed on high-speed friction and wear tester with electric current. The results show that the friction coefficient is generally maintained between 0.24 and 0.37 . In the absence of electric current, the coefficient of friction is higher than that in the presence of electric current. The wear rate of carbon strip materials is generally not more than $0.014 \mathrm{~g} / \mathrm{km}$. In particular, the wear rate under the electric current of $240 \mathrm{~A}$ is 14 times more than that in the absence of electric current. By observing the scar of worn surface with optical microscope, it can be found that there are obvious slip scars and arc erosive pits. The dominated wear mechanisms are abrasive wear and arc erosion in electrical sliding frictional process.
\end{abstract}

Keywords: Arc erosion, friction and wear, high-speed, wear mechanism.

\section{INTRODUCTION}

The pantograph-catenary system is composed of collector strip, supporting pantograph, contact wire, droppers, supporting rods, carrier and suspension in electrified railway, as shown in the Fig. (1). The driving power of the electric railway locomotive has been up to $8000 \sim 10000 \mathrm{~kW}$ [1-3], which is transmitted to the running train through a collector strip rubbing against a contact wire. The service life of pantograph/catenary system mainly depends on the wear life of the pantograph strip and contact wire materials. Increasing wear service life of the collector strips is a main concern to operators and investigators. From the viewpoint of friction, the wear service life depends on wear mechanisms occurring in the process of electrical sliding friction. In the literature, several wear mechanisms such as abrasive wear, adhesive wear, arc erosion and oxidation wear were reported in electrical sliding frictional process [4-6]. The effect of electric current on the wear mechanism was emphasized in an action of Joule heat and arc discharge heat [7, 8]. Especially, several investigators reported that wear of contact strip materials is related to interface debris generated on contact surfaces [5, 9-11]. With increase in high-speed train, the wear of the collector strip and contact wire materials becomes severer and severer in a pantograph strip rubbing against a contact wire. In order to reveal the effects, influence of electric current and normal force on tribology properties of carbon strip rubbing against copper contact wire is used to investigate damage mechanism of contact materials for pantograph-catenary system.

*Address correspondence to this author at the Department of Mechanical Engineering, Hubei Engineering University, Xiaogan 432000, P.R. China; Tel: +8613871930523; Fax: +86-0712-2345540;

E-mail: dingtao347@126.com

\section{EXPERIMENT DETAILS}

The tester has been introduced in the previous texts [3, $12,13]$. At present, a ring-on-block tester was developed for the present test purpose. The schematic of test ring and collector strip/copper contact wire couple is shown in Fig. (2). The rotational disc is driven by a variable-frequency motor of $58 \mathrm{~kW}$. The sliding velocity of the rotational disc with respect to the collector strip varies from $0-400 \mathrm{~km} / \mathrm{h}$. And the collector strip frame can oscillate at a frequency of $0.3-3 \mathrm{~Hz}$ in the vertical direction. The collector strip frame is driven by a servo motor to provide a steady normal force between the collector strip and the contact wire. And the normal force varies from 10 to $300 \mathrm{~N}$. In the tests, the normal force $F_{\mathrm{n}}$ is set to 30,90 and $150 \mathrm{~N}$. The electric current intensity $I$ of $0,180,200,220$ and 240 A are chosen. The sliding velocity $v$ is set to $160 \mathrm{~km} / \mathrm{h}$ and the sliding distance of each test is set to $200 \mathrm{~km}$. Before each test, the carbon strips are polished with 1000 and 1200 abrasive papers and are cleaned with alcohol. Its surface roughness is about $\mathrm{R}_{\mathrm{a}}=1.6 \mu \mathrm{m}$. The contact wire surface is abraded with 1600 abrasive paper to obtain a good contact surface. Run-in between the carbon strip and contact wire is carried out at a sliding speed of $15 \mathrm{~km} / \mathrm{h}$ for 5 minutes in order to obtain a good contact of sliding contact coupe.

\section{RESULTS AND DISCUSSIONS}

\subsection{Friction Coefficient}

The variation of friction coefficient with electric current and normal force is presented in Fig. (3). It can be seen that the friction coefficient is generally maintained between 0.24 and 0.37 in the process of the carbon strip rubbing against the copper contact wire. The friction coefficient without electric current is higher than that with electric current. And the friction coefficient reduces with increasing intensity of 

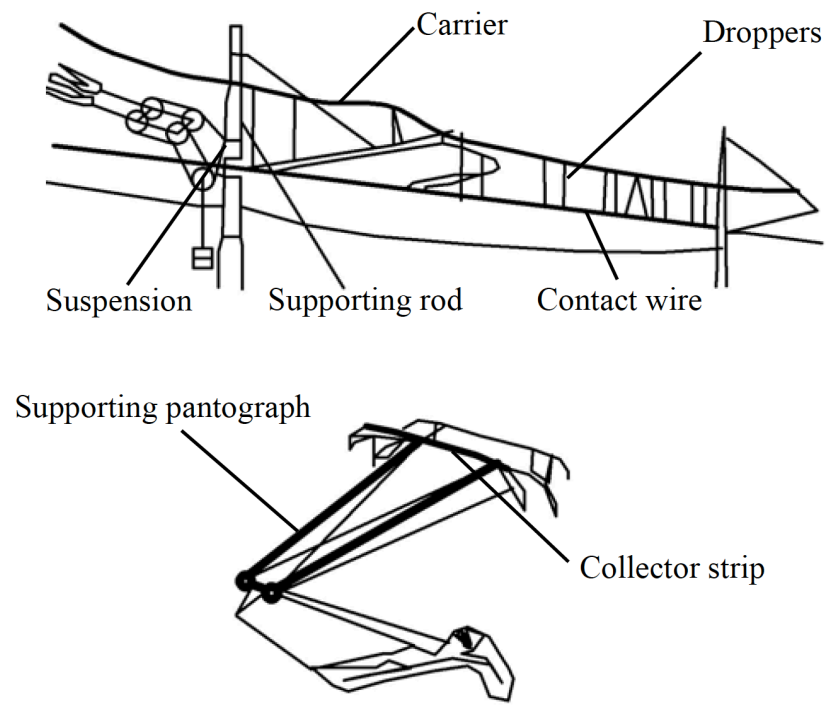

Fig. (1). Pantograph-catenary system.

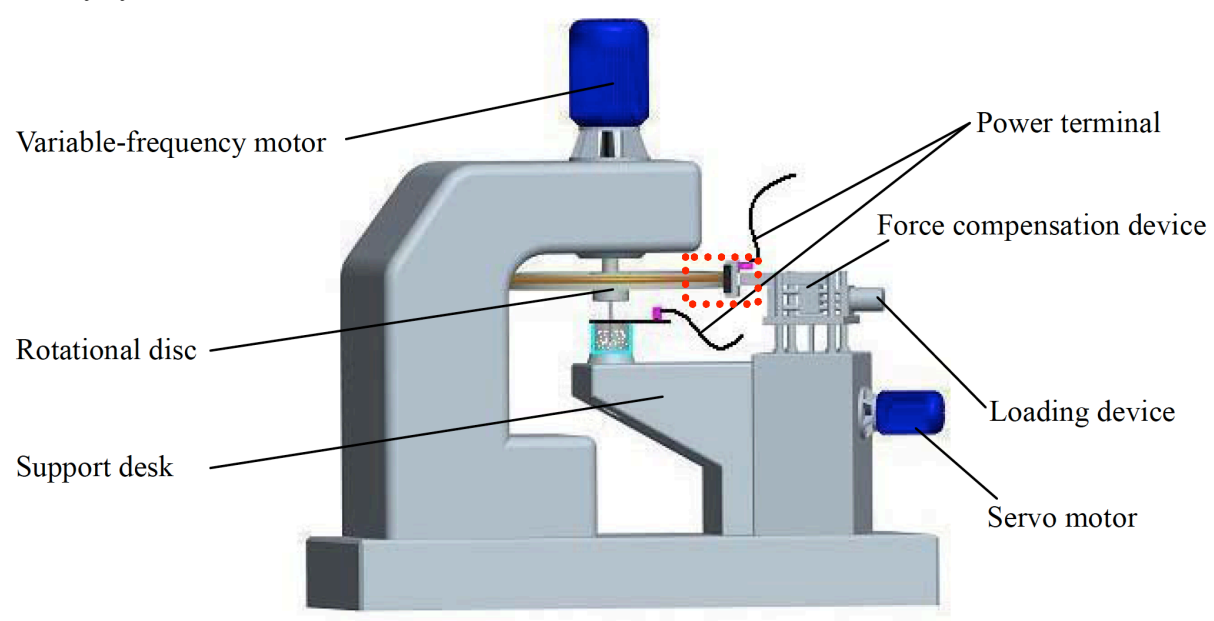

(a)

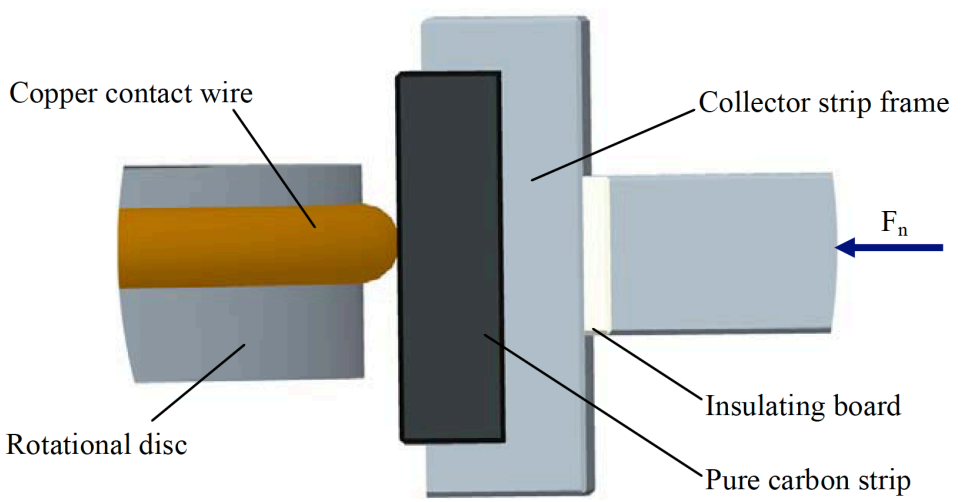

(b)

Fig. (2). Test rig: (a) schematic of the tester; (b) collector strip/copper contact wire couple.

electric current. That is attributed to the formation of an oxide layer at the contact interface. The oxide layer is favored by high temperature oxidation due to an accumulation of Joule heat, frictional heat and arc heat $[7,8$, 14]. Moreover, the friction coefficient increases with decrease in normal force. As the normal force reduces, the arc discharge becomes stronger and stronger in the contact interface. The arc erosion and thermal wear are a key factors to result in severe wear due to arc discharge. The accumulation and removal of debris lead to the increase in friction coefficient [15-17]. 


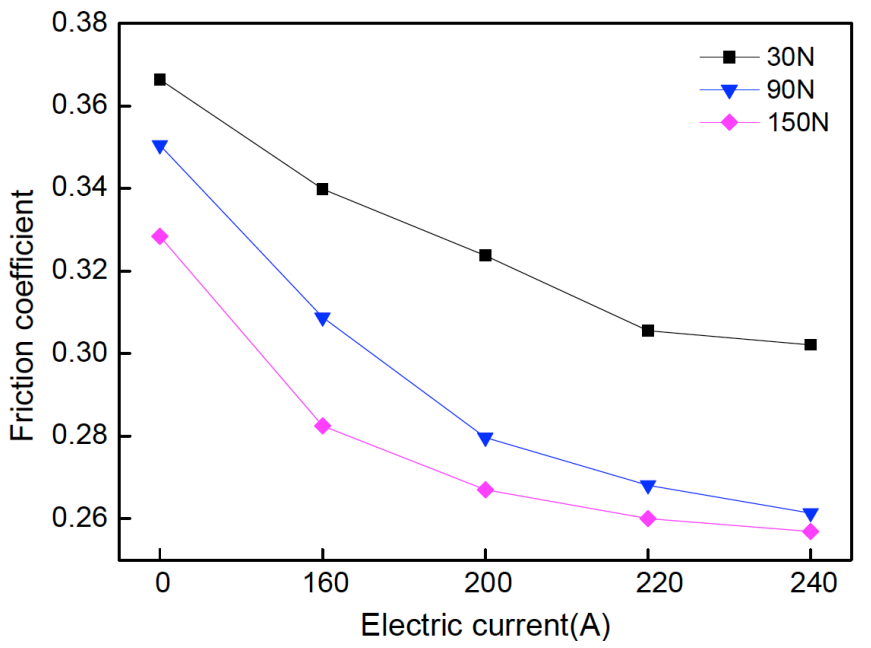

Fig. (3). Variations of friction coefficient with electric current and normal force.

\subsection{Wear Rate of Carbon Strip}

Fig. (4) shows the effect of electric current and normal force on wear rate of carbon strip. From Fig. (4), it can be seen that the wear rate without electric current is the lowest, about $0.0013 \mathrm{~g} / \mathrm{km}$. And the wear rate with electric current is 14 times more than that without electric current. It can also be found that the wear rate increases with increasing electric current, and decreases with increasing normal force. Under the same electric currents, the wear rates of the carbon strip increase slightly with increase in sliding velocity. At the same time, it can also be found that the wear rate of the pure carbon strip increases with increasing electric current. The wear rate of the carbon strip is the lowest without electric current, whose value is only $0.00096 \mathrm{~g} / \mathrm{km}$. As the electric current increases, the wear rate of pure carbon strip significantly increases. When the electric current is equal to $240 \mathrm{~A}$, the wear rate reaches $0.0135 \mathrm{~g} / \mathrm{km}$. That result suggests that the electric current plays a role on accelerating materials damage due to arc erosion and thermal wear.

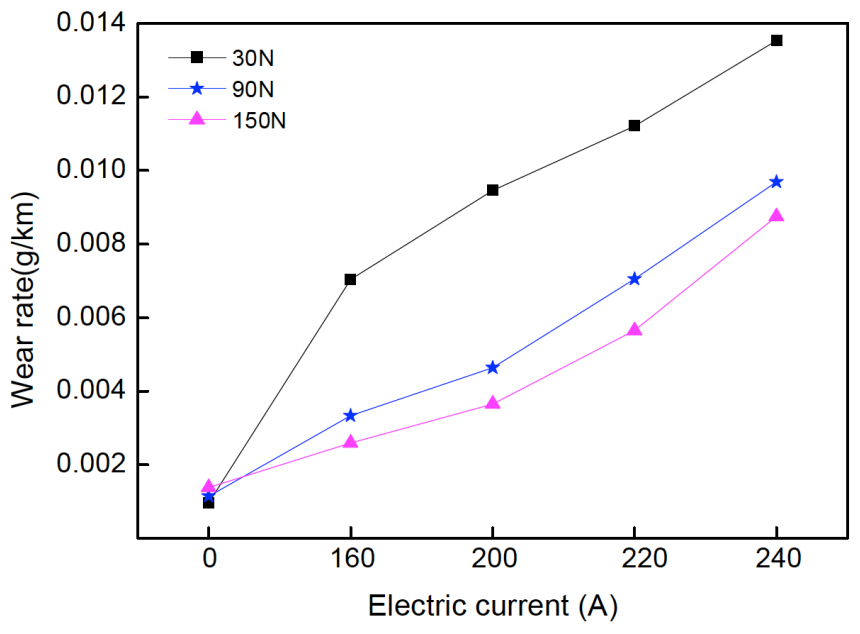

Fig. (4). Variation of wear rate with electric current and normal force.

\subsection{Worn Surface Morphology of Carbon Strip}

Fig. (5) shows the surface morphology of carbon strip after wear. Fig. (5a) shows the area and depth of worn scar being very small without electric current. It can be seen that there is a great deal of wear debris and worn scars on the strip surface. However, the area and depth of worn scars increase significantly when the electric current is equal to

(a)

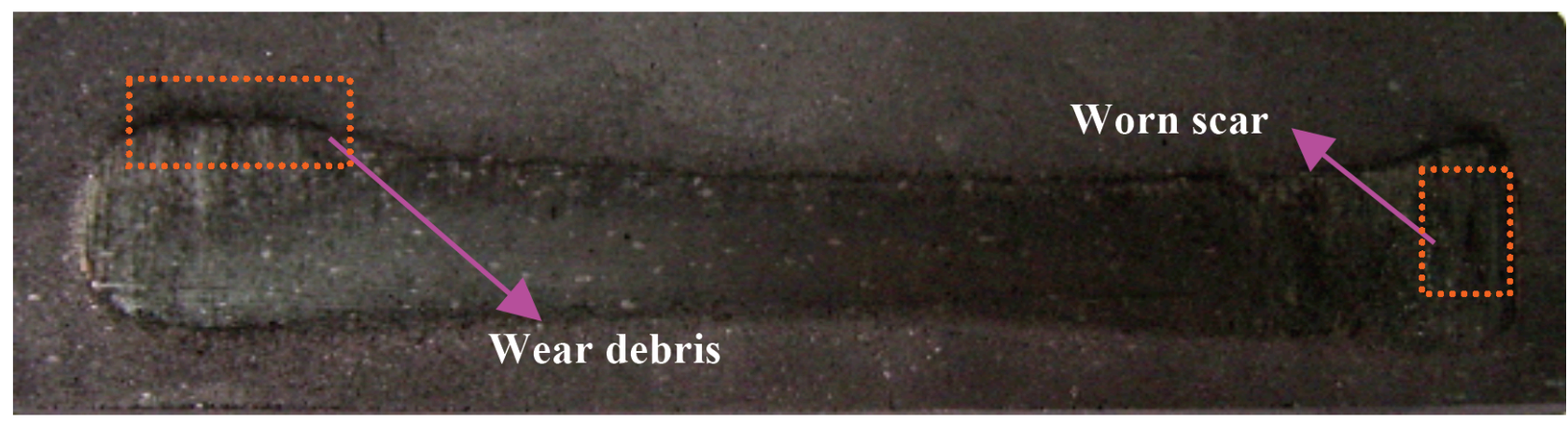

(b)

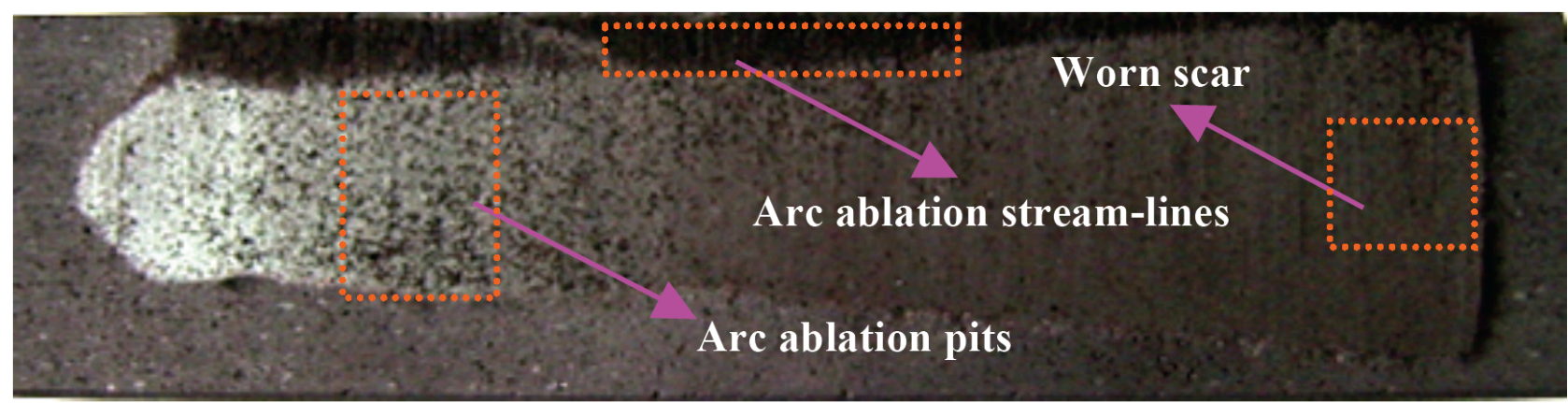

Fig. (5). Surface morphology of carbon strip after wear: (a) $I=0$; (b) $I=200$ A. 



Fig. (6). Optic morphology of carbon strip after wear: (a) $I=0$; (b) $I=240$ A.

200 A. It can be seen that there are arc ablation pits, worn scar and dark arc ablation stream-lines, as shown in Fig. (5b). In the electrical sliding process, there is a great deal of spark discharge and arc discharge. The arc ablation pits and arc ablation stream-lines occur in the worn surface of carbon strip due to arc discharge. At the same time, it can be found that the temperature of contact couple reaches $300^{\circ} \mathrm{C}$ at the electric current of 200A. The high temperature leads to the occurrence of abrasive wear. Therefore, it suggests that abrasive wear and arc erosion occur in the process of electrical sliding friction.

\subsection{Surface Micro-morphology in Worn Region}

Fig. (6) shows the microstructure of a worn surface of the carbon strip with and without electric current. It can be seen from Fig. (6a) that there are clear sliding scars and wear debris on the worn surface. It suggests that the main wear mechanism is abrasive wear without electric current. From Fig. (6b), it can be found that clear sliding scars, arc ablation pits and metal melting exist on the worn surface. It also suggests that the main wear mechanisms are abrasive wear and arc erosion with electric current.

\section{CONCLUSION}

The normal force, sliding velocity and electric current have distinct effects on friction and wear properties of carbon strip/copper contact wire. The friction coefficient generally maintained between 0.24 and 0.37 . The wear rate of carbon strip is not more than $0.014 \mathrm{~g} / \mathrm{km}$. When the electric current is equal to $240 \mathrm{~A}$, the wear rate is 14 times more than that without electric current. Abrasive wear and arc erosion are the major wear mechanisms in the process of electrical sliding friction.

\section{CONFLICT OF INTEREST}

The authors confirm that this article content has no conflict of interest.

\section{ACKNOWLEDGEMENTS}

It is a project supported by the financial supports from Project of Education Department of Hubei Province for
Young Teachers into the Enterprise (XD2012390), Projects of Education Department of Hubei Province (B2013025 and Q20142704), and Hubei Co-Innovation Center for Utilization of Biomass Waste (No. SWZ034).

\section{REFERENCES}

[1] Y. Watanabe, "High-speed sliding characteristics of Cu-Sn-based composite materials containing lamellar solid lubricants by contact resistance studies", Wear, vol. 264, no. 7-8, pp. 624-631, 2008.

[2] G. Bucca, and A. Collina, "A procedure for the wear prediction of collector strip and contact wire in pantograph-catenary system", Wear, vol. 266, no. 1-2, pp. 46-59, 2009

[3] T. Ding, G.X. Chen, X. Wang, M.H. Zhu, W.H. Zhang, and W.X Zhou, "Friction and wear behaviour of pure carbon strip sliding against copper contact wire under AC passage at high speeds", Tribology International, vol. 44, pp. 437-444, 2011.

[4] S. Kubo, and K. Kato, "Effect of arc discharge on the wear rate and wear mode transition of a copper-impregnated metallized carbon contact strip sliding against a copper disk", Tribology International, vol. 32, no. 7, pp. 367-378, 1999.

[5] S.G. Jia, P. Liu, F.Z. Ren, B.H. Tian, and M.S. Zheng, "Sliding wear behavior of copper alloy contact wire against copper-based strip for high-speed electrified railways", Wear, vol. 262, no. 7-8, pp. 772-777, 2007.

[6] A. Senouci, J. Frene, and H. Zaidi, "Wear mechanism in graphite copper electrical sliding contact", Wear, vol. 225-229, no. 2, pp. 949-953, 1999

[7] G. X. Chen, F. X. Li, L. Dong, M. H. Zhu, and Z.R. Zhou, "Friction and wear behavior of stainless steel rubbing against copper-impregnated metalized carbon", Tribology International, vol. 42, no. 6, pp. 934-939, 2009.

[8] H. Nagasawa, and K. Kato, "Wear mechanism of copper alloy wire sliding against iron-base strip under electric current", Wear, vol. 216, no. 2, pp. 179-183, 1998.

[9] D.H. He, and R. Manory, "A novel electrical contact material with improved self-lubrication for railway current collectors", Wear, vol. 249 , no. 7 , pp. $626-636,2001$

[10] H. Zhao, G.C. Barber, and J. Liu, "Friction and wear in high speed sliding with and without electrical current", Wear, vol. 249, no. 56, pp. 409-414, 2001.

[11] T. Ding, G. X. Chen, M. H. Zhu, W.H. Zhang, and Z.R. Zhou, "Influence of the spring stiffness on friction and wear behaviors of stainless steel/ copper-impregnated metallized carbon couple with electrical current", Wear, vol. 267, no. 5-8, pp. 1080-1086, 2009.

[12] H.J. Yang, G. X. Chen, S. D. Zhang, and W.H. Zhang, "Effect of the vibration on friction and wear behavior between the carbon strip and copper contact wire pair", Journal of Engineering Tribology, vol. 226, no. 8, pp. 1-7, 2012

[13] G.X. Chen, H. J. Yang, W. H. Zhang, X. Wang, S.D. Zhang, and Z.R. Zhou, "Experimental study on arc ablation occurring in a 
contact strip rubbing against a contact wire electrical current", Tribology Int., vol. 61, no. 5, pp. 88-94, 2013.

[14] A. Bouchoucha, S. Chekroud, and D. Paulmier, "Influence of the electrical sliding speed on friction and wear processes in an electrical contact copper-stainless steel”, Applied Surface Science, vol. 223, no.4, pp. 330-342, 2004.

[15] N.P. Suh, and H.C. Sin, "The genesis of friction", Wear, vol. 69, no. 1 , pp. $91-114,1981$.
[16] Y. Feng, M. Zhang, and Y. Xu, "Effect of the electric current on the friction and wear properties of the CNT-Ag-G composites", Carbon, vol. 43, no. 13, pp. 2685-2692, 2005.

[17] L. Dong, G. X. Chen, M. H. Zhu, and Z. R. Zhou, "Wear mechanism of aluminum-stainless steel composite conductor rail sliding against collector shoe with electric current", Wear, vol. 263, no.1-6, pp. 598-603, 2007.

(C) Ding et al.; Licensee Bentham Open.

This is an open access article licensed under the terms of the Creative Commons Attribution Non-Commercial License (http://creativecommons.org/licenses/ by-nc/3.0/) which permits unrestricted, non-commercial use, distribution and reproduction in any medium, provided the work is properly cited. 